\title{
Racismo à brasileira ou racismo sem racistas: colonialidade do poder e a negação do racismo no espaço universitário
}

\author{
Ângela Figueiredo \\ Doutora em Sociologia (Instituto Universitário de Pesquisas do Rio de Janeiro) \\ Professora da Universidade Federal do Recôncavo da Bahia \\ Cachoeira, BA, Brasil \\ angelafigueiredo@yahoo.com \\ Ramón Grosfoguel \\ Doutor em Sociologia (Temple University) \\ Professor da University of California, Berkeley \\ Berkeley, Califórnia, Estados Unidos \\ grosfogu@berkeley.edu
}

\begin{abstract}
Resumo A adoção do sistema de cotas nas universidades públicas brasileiras tem suscitado intenso e caloroso debate entre os intelectuais brasi leiros antirracistas, que almejam a construção de uma sociedade mais justa, mas que se colocam em posições contrárias quando o tema é a implementação de cotas. A reação negativa desses interlocutores brancos e mestiços claros, de esquerda e de direita, com relação às políticas de cotas, deriva da preocupação com a possibilidade de criarmos um Brasil racializado, destruindo, assim, o nosso tão caro discurso da mestiçagem. A bordamos neste texto 0 tema da perspectiva da colonialidade do poder articulada por A níbal Q uijano. Dessa perspectiva, nos parece importante entender a importância da geopolítica do conhecimento, já que é determinante compreendermos a localização epistêmica e as posições tomadas pelos diferentes atores sociais.
\end{abstract}

Palavras-chave desigualdades raciais; hierarquias raciais; colonialidade do poder; geopolítica do conhecimento e modernidade.

A DÉCADA DE 1990 CONSTITUI um período singular na história das relações raciais brasileiras. A final de contas, é no governo de Fernando $\mathrm{H}$ enrique $\mathrm{C}$ ardoso que, pela primeira vez, se admite, oficialmente, a existência de preconceito e de discriminação raciais em nossa sociedade. Isto veio, do ponto vista político, ao encontro das conclusões a que haviam chegado diversas pesquisas realizadas desde a década de 1970, que deslocavam a crença na democracia racial brasi leira, paradigma interpretativo sobre a nossa sociedade que teve na obra $\mathrm{C}$ asa grande \& senzala, de Gilberto Freyre, sua grande representação.

Esse movimento, que se consolida na década de 1990, contou, fundamentalmente, com a contribuição de dois atores: 0 ativismo negro e as C iências Sociais. Do ponto de vista da produção acadêmica nesse âmbito, é incontestável a contribuição de alguns autores que se encarregaram de demonstrar, já na década de 1970, as desigualdades raciais na configuração do mercado de trabalho e, dos seus desdobramentos em períodos posteriores, nas pesqui sas sobre as desigualdades no acesso à educação e nos desníveis de renda entre negros e brancos. 0 argu- 
mento desenvolvido por essa nova vertente sociológica opunha-se tanto à tese anterior, que buscava entender as manifestações de preconceito e de discriminação raciais apenas nas relações interpessoais e menos na estrutura - por isso mesmo, a importância atribuída à mobilidade ascendente e aos casamentos ou uniões interraciais -, quanto à tese, inicialmente formulada por Florestan Fernandes, em 1972, de que as desigualdades raciais no Brasil eram resquícios de um passado escravista e que tenderiam a desaparecer a partir das novas relações de trabal ho presentes no sistema capitalista.

A tese defendida por $\mathrm{C}$ arlos $\mathrm{H}$ asenbalg, em 1979, por exemplo, argumentava que o racismo e a discriminação racial resultavam da competição só existente no capitalismo, no sentido de que só a partir da concorrência em que tal sistema viceja é que veríamos surgir a discriminação racial e o racismo sob sua formulação moderna. Entretanto, a perspectiva da colonialidade do poder articulada por A níbal Q uijano (1993, 1998 e 2000) considera que o racismo e a construção de categorias raciais começam com a formação da divisão internacional do trabalho do sistema-mundo europeu capital ista/ patriarcal moderno/colonial no final do século X V, em 1492.

É importante destacar três importantes aspectos: primeiro, as diferentes formas de interpretação das desigualdades raciais e do racismo na sociedade brasi leira; segundo, a evidência, como mostra a perspectiva latino-americana, de que o racismo não é um fenômeno moderno; terceiro, a necessidade de estabelecer, desde já, uma ruptura entre o racismo contemporâneo e as teorias raciais ocidentais prevalecentes no século X IX, mais conhecidas entre nós, que eram fundamentalmente baseadas na crença da diferença biológica. Pois sabemos que, na modernidade, os racismos culturais e biológicos coexistem, porém, dependendo do contexto histórico-colonial, um prevalece sobre 0 outro.

Estudos genéticos mais recentes, inclusive desenvolvidos no Brasil, mostram que, do ponto de vista biológico, somos todos mestiços e, para utilizar uma linguagem mais moderna, somos quase todos afrodescendentes, euro-descendentes e índio-descendentes, como demonstrado por Pena e Bortolini (2004). $\mathrm{N}$ esse sentido, os achados presentes nos estudos genéticos, nesse âmbito, não servem como base para 0 argumento a ser utilizado por racistas e antirracistas, mas para reafirmar apenas que a raça é uma construção social e, assim sendo, o nosso diálogo não deve ser estabelecido no campo da natureza, mas, sim, no da cultura, já que o nosso diálogo tem de ser estabelecido no campo das relações sociais e das diferenças histórica e socialmente construídas, em que o fenótipo, e não o genótipo, é importante. D ito de outro modo, se fazemos parte de uma nação em que todos somos misturados, mestiços do ponto de vista biológico, somos socialmente vistos e divididos entre os mestiços mais daros e mestiços mais escuros.
N este texto, gostaríamos de apresentar algumas reflexões sobre a experiência negra na universidade, tomando como ponto de partida os diálogos e as conversas informais com os estudantes negros brasileiros da pós- graduação, assim como com alguns dos estudantes que participaram do curso Fábrica de Ideias. O s estudantes negros são maioria no curso e quase todos desenvolvem pesquisas relacionadas com a temática das desigualdades raciais e da identidade negra em diferentes perspectivas.

Para tanto, o texto está estruturado em três partes: na primeira, apresentamos a perspectiva da colonialidade do poder para entender tanto as hierarquias raciais existentes nas universidades brasileiras quanto alguns aspectos relativos ao debate so bre as cotas; na segunda, dada a importância do tema das desigualdades ou das hierarquias raciais no Brasil, apresentamos, ainda que brevemente, a formação do campo de estudos definido como Estudos das R elações $R$ aciais no Brasil e as mudanças e tensões ocorridas a partir da entrada em cena de pesquisadores negros; já na terceira, discorremos sobre as políticas descoloniais na produção do conhecimento, e, finalmente, no quarto ponto, retomamos as questões relativas à colonialidade do poder e à negação do racismo no espaço acadêmico.

\section{Colonialidade do poder no Brasil e o debate sobre a implementação de políticas de cotas}

A pirâmide social, como é descrita a estrutura da sociedade brasileira, expressa muito bem a manutenção das hierarquias raciais existentes desde o perío do escravista, conforme apresentada com base na perspectiva da colonialidade do poder. Está fundamentalmente dividida entre as ocupações desempenhadas pelos mestiços mais daros - que estão sobrerrepresentados nas universidades, sobretudo nos cursos de maior status e prestígio, nos cargos de direção e chefia e nas funções de comando, no Judiciário e na política, para citar alguns exemplos - e os mestiços mais escuros - subrepresentados em todas as ocupações mencionadas e sobrerrepresentados nas ocupações subalternas, principalmente naquelas que pagam baixos salários e que envolvem a força física. A lém disso, os mestiços mais escuros são frequentemente estereotipados, quando não invisibilizados, nas representações sobre o Brasil moderno, presentes, por exemplo, na mídia.

Isto faz parte da colonialidade do poder existente no Brasil e em outros países das A méricas. Como observou A níbal Q uijano (1993, 2000), as independências latino-americanas e norte-americanas, desde o final do século XVIII, com exceção do Haiti, 
foram "independências coloniais". Esse paradoxo se refere ao fato de que a luta pela independência dos brancos crioulos (poderíamos dizer mestiços claros) nunca descolonizou a hierarquia étnico-racial do poder político, econômico e social construído durante o colonialismo europeu nas A méricas. 0 Estado independente foi dominado e controlado pelos filhos dos espanhóis, portugueses e britânicos nas A méricas, deixando intactas as hierarquias raciais existentes. A inda que os Estados fossem nominalmente independentes dos impérios europeus, de fato eram coloniais no que diz respeito a dois processos: primeiro, as relações de poder na divisão internacional do trabalho em âmbito global, com a periferia explorada pelos impérios europeus e mais recentemente pelo império norteamericano; segundo, e mais importante para o nosso tema, as relações de poder raciais e de dasse no interior de seu território. O s negros, pardos, mestiços e indígenas mantiveram- se nas posições mais baixas e mais exploradas da sociedade.

A abolição da escravatura foi um processo importante, mas não suficiente para a descolonização das sociedades. N o Brasil, a "independência sem descolonização" manteve os negros, pardos e indígenas excluídos, explorados, marginalizados, segregados dos espaços de poder social, cultural, econômico, político e educativo. $\mathrm{N}$ ão obstante estejamos observando a segregação e a exclusão que a colonialidade do poder tem exercido sobre a população mestiça escura em nível educacional.

Esperamos que a denominação utilizada neste texto - mestiços daros e mestiços escuros - convença aqueles que, mesmo sensíveis às desigualdades sociais, demonstram preocupação em ver o Brasil do futuro dividido entre negros e brancos. A final de contas, estaremos contribuindo para a construção de um Brasil racializado, país em que a mestiçagem, tão cara à formação da nossa identidade nacional, perderá o seu valor? E que exemplo daremos ao mundo, que cada vez mais se vê envolvido em conflitos de natureza étnico-racial? Será que não podemos mais ocupar o lugar que tivemos quando das pesquisas desenvolvidas pela U nesco na década de 1950, em que éramos vistos como um exemplo, um modelo da boa convivência a ser seguido por outros países? Q uais as consequências da utilização de identificações raciais na implementação de políticas públicas? Será que não estaríamos nomeando e, portanto, oficializando as desigualdades a que tanto temos resistido em identificar como sendo de natureza racial? E sua formulação mais sintética: combate- se o racismo com outra forma de racismo?

Todas estas questões vêm à tona quando o debate gira em torno da implementação da política de cotas nas universidades públicas brasileiras. Aqui, buscamos dialogar com pessoas sensíveis às desigualdades sociais, marca prioritária da nossa sociedade, aqueles que acreditam na necessidade de combatê-las e que se mostram verdadeiramente preocupados com o futuro da sociedade brasileira. Aqueles que, empenhados em demonstrar a eficácia de políticas universalistas, e mesmo por receio de vislumbrar uma sociedade racializada, uma sociedade em que a mestiçagem perca 0 seu valor, têm buscado alternativas e demonstrado a importância de adotarmos outras medidas redistributivas - a exemplo da realização de cursos noturnos, de pré-vestibulares gratuitos, ou redistribuição de vagas ociosas nas universidades, sugestões bem-vindas, que não podem ser vistas apenas como opostas às cotas. São iniciativas baseadas muito mais na desigualdade de classe do que de cor/raça e que certamente não comprometeriam a nossa etiqueta racial nem destruiriam a nossa histórica cordialidade - mecanismo existente na sociedade brasileira, segundo o qual cada um ocupa o seu lugar hierárquica e socialmente determinado, no âmbito de relações desiguais presentes no cotidiano, e cuja expressão popular "cada macaco no seu galho" é o melhor exemplo.

$\mathrm{N}$ essa perspectiva, nos parece determinante entender a importância da geopolítica do conhecimento (M ignolo, 2000) no debate sobre cotas no Brasil, já que é determinante compreendermos a localização epistêmica e as posições tomadas pelos diferentes atores sociais. É interessante observar a reação negativa de intelectuais e acadêmico brancos e mestiços claros, de esquerda e de direita, com relação às políticas de cotas: todos parecem preocupados com a possibilidade de criarmos um Brasil racializado, destruindo, assim, o nosso tão caro discurso da mestiçagem. É curioso o fato de que nenhum indivíduo negro, ou melhor, mestiço escuro, contrário ou favorável à implementação da política de cotas, tenha reivindicado o discurso da mestiçagem na construção do seu próprio argumento; ao contrário, quase todos os mestiços claros, os brancose quase brancos, invocam as dificuldades da implementação de tal política, reivindicando tal argumento.

Ao que parece, evocar o discurso da mestiçagem tem sido uma estratégia utilizada pelos autores brancos entre si e, como tal, constitui aquilo que no ditado popular denomina-se "conversa de branco". Trata-se, portanto, de uma prática histórica instituída nas $\mathrm{C}$ iências Sociais brasileiras, que reproduz a mesma lógica que operou no debate sobre a mestiçagem e a identidade nacional ate os anos 30 , em que os intelectuais brancos decidiam o futuro da nação através da solução para o problema da raça no Brasil e sobre o papel ocupado pelo mulato na hierarquia racial brasileira. Entretanto, jamais lemos um artigo sequer escrito por um mulato em que os benefícios ou vantagens de ser mulato no Brasil fossem abordados. Ao que parece, o debate ocorria em outro âmbito, contando apenas com a presença de pesquisadores brancos ou mestiços muito claros, e o mulato, silenciado, lia e aprendia sobre os benefícios e as vantagens de ser mestiço no Brasil. 
A importância dos Estudos das Relações Raciais no Brasil e a emergência de sujeitos políticos negros nas universidades brasileiras

O campo de estudos conhecidos como Estudos das $R$ elações $R$ aciais no Brasil constitui o objeto de conhecimento historicamente produzido por acadêmicos mestiços claros, brancos ou quase brancos, cuja epistemologia baseia-se no estudo sobre negros, por isto mesmo, a noção de estudos sobre as "relações raciais" mantém o mito de uma horizontalidade entre os grupos racial mente diferenciados. Por isso mesmo julgamos ser mais adequado falarmos de "hierarquias raciais", já que enfatizaríamos a verticalidade das relações sobre a suposta horizontalidade expressa na definição "Estudos das R elações R aciais".

Diferentemente de outros países, o interesse em entender os problemas das "relações raciais" constituiu uma preocupação que antecedeu a institucionalização da Sociologia brasileira, a partir da criação da Escola Livre de Sociologia e Política, em 1933, e da criação da U niversidade de São Paulo (U SP), em 1934. Inicialmente presente no relato dos viajantes e, em seguida, na obra dos ensaístas, a exemplo de Sílvio R omero, $M$ anoel Bonfim, O liveira Viana e, posteriormente, a partir dos trabalhos de Gilberto Freyre (O liveira, 1995).

N esse sentido, a preocupação com as questões de natureza racial sempre despertou o interesse dos estudiosos, independentemente dos enfoques e das agendas acadêmicas e políticas. A primeira geração estava preocupada com o futuro da nação brasileira, condenada pelos efeitos "maléficos" da mistura de raças. $\mathrm{N}$ esse período, os estudos vislumbravam uma única saída: o clareamento ou o embranquecimento da população brasileira a partir da mistura das raças em gerações consecutivas, ou seja, havia uma crença de que mestiçagens sucessivas levariam, inevitavelmente, ao desaparecimento da população negra. A partir dos trabal hos de Freyre, há uma interpretação do B rasil numa chave cultural; para alguns autores, há em Freyre uma valorização da mistura racial e cultural. 0 cultural ismo de Freyre acabou por consolidar a crença na democracia racial brasileira, paradigma interpretativo vigente pelo menos até o início dos anos 90.

0 terceiro momento é caracterizado pela institucionalização da Sociologia e, consequentemente, pela adoção de técnicas de pesquisa e reflexões teóricas mais rigorosas. Aqui é importante destacar a figura de D onald Pierson e a influência que exercerá sobre a Sociologia brasileira a Escola de Chicago. Pierson desenvolve uma importante pesquisa sobre as "relações raciais" na B ahia, em que acaba por corroborar, ou fortalecer, a crença na inexistência do preconceito racial, enfatizan- do que o preconceito no Brasil é de classe.

Ainda relacionado a esse terceiro momento, podemos mencionar as pesquisas desenvolvidas no âmbito do que convencional mente chamamos de Projeto U nesco, realizadas em diferentes estados brasileiros. $G$ rosso modo, poderíamos dizer que a escolha do Brasil pela U nesco mantinha uma estreita relação com as preocupações advindas do pós-guerra e com as consequências da crença na existência de raças e do racismo. o Brasil, portanto, teria um bom exemplo a dar ao mundo, qual seja, a convivência harmônica entre as diferentes raças. As articulações políticas e os motivos que levaram à escolha do Brasil para a realização da pesquisa, assim como a escolha do coordenador e dos pesquisadores envolvidos nesse projeto, estão bem descritos na tese de Chor M aio (1997).

$\mathrm{N}$ ão podemos deixar de mencionar as pesquisas realizadas no âmbito da A ntropologia, que enfocaram majoritariamente a religiosidade e alguns aspectos específicos da cultura negra. É importante destacar também o peso da tradição dos estudos sobre cultura e personalidade na A ntropologia norte-americana, que influenciaram Freyre e M elville H erskovits, os quais, por sua vez, exerceram influência diretamente sobre A rthur $\mathrm{R}$ amos e, consequentemente, sobre as pesquisas antropológicas acerca da religiosidade negra. Independentemente das perspectivas e das abordagens, as pesquisas foram e ainda são realizadas com a população negra-mestiça, o que acabou por se configurar no que Guerreiro $R$ amos denominou de "o problema dos negros brasileiros".

É importante destacar algumas mudanças de enfoque nos estudos sobre as "relações raciais" empreendidos a partir do final dos anos 70, sobretudo com os estudos realizados por C arlos H asenbalg (1979) e em trabalhos posteriores que demonstravam as desigualdades no acesso à educação e nos desníveis de renda entre negros e brancos, aliados às denúncias empreendidas pelo então recém-formado $M$ ovimento $N$ egro U nificado sobre o preconceito e a discriminação racial no Brasil.

Esta breve descrição sobre como se configurou o campo dos "Estudos das R elações R aciais" no Brasil, ao invés de Estudos das $\mathrm{H}$ ierarquias $\mathrm{R}$ aciais, como sugerimosacima, objetiva demonstrar, num primeiro momento, não só a importância dos estudos sobre as "relações raciais" nas C iências Sociais brasileiras, bem como evidenciar a existência de um campo institucionalizado e hegemonizado por perspectivas e epistemologias euro-brasileiras, em que já havia uma perspectiva comparativa com os Estados U nidos.

Ainda que tradicionalmente existisse essa perspectiva, sabemos que historicamente os pesquisadores compararam, principalmente, al guns aspectos, tais como: a importância da raça na construção do Estado-nação; a escravidão negra; a própria definição da raça e do racismo nas duas sociedades (Skidmore, 1974 
e 1980). Trata-se, portanto, da análise de macrofenômenos, de diferentes ideologias e das construções sociais acerca da raça (N ogueira, 1998). A conclusão depende dos diferentes pontos de vista. Para a maioria dos pesquisadores brasileiros, assim como para alguns pesquisadores norte-americanos, o racismo no Brasil é "melhor" do que aquele existente nos Estados U nidos, dado que aqui não houve segregação racial oficial, assim como não houve impossibilidade/ interdição com relação aos casamentos interraciais, o que possibilitou a existência de um maior número de mestiços e, consequentemente, uma diluição das fronteiras e do preconceito racial. A partir da década de 1970, pesquisadores afro-americanos e alguns ativistas negros passaram a considerar que o racismo no Brasil é pior do que aquele existente nos Estados U nidos, já que a dinâmica racial no Brasil impossibilitou que os negros-mestiços desenvolvessem uma consciência racial.

Tradicional mente, os pesquisadores não estavam interessados em compreender as dinâmicas relacionadas à formação e ao desenvolvimento doscampos. A inda que alguns pesquisadores americanos tenham sido fundamental mente importantes na institucional ização das C iências Sociais brasileiras, como D onald Pierson (Corrêa, 2003). De um modo geral, os pesquisadores negligenciaram a ausência de pesqui sadores negros num campo que estava principalmente voltado para a compreensão da população afro-brasileira. C ontudo, é fundamental para o desenvolvimento de nosso argumento refletir sobre a formação dos campos.

African-A merican Studies é o nome utilizado para definir o campo que estuda a experiência negra nos Estados U nidos. Como demonstrou $\mathrm{M}$ aldonado (2006), o surgimento dos estudos de minoria nos Estados U nidosresultou, por um lado, do final da G uerra Fria e do menor interesse pelos estudos de área e, por outro, da pressão exercida pelos movimentos sociais quer dizer, havia uma necessidade não só de produzir uma reflexão sobre as minorias étnico-raciais, como também de incorporar membros dessas populações nas universidades não somente como estudantes, mas, principalmente, como professores/pesquisadores. De fato, o surgimento do primeiro D epartament of Black Studies, na San Francisco State U niversity, em 1968, resultou da pressão dos movimentos negros. Talvez, por isso, haja uma estreita relação entre os temas tratados pelo movimento social e político e pelas pesquisas acadêmicas. D ito de outro modo, há uma maior conexão entre as questões acadêmicas e as questões que realmente importam para a comunidade/ população afro-americana. A consequência disso é que existe ou existia maior proximidade entre a demanda dos movimentos sociais e as pesquisas acadêmicas.

Como vimos, a origem do programa de A fricanA merican Studies é muito diferente dos Estudos das R elações $R$ aciais no Brasil. N este, somente a partir do final da década de 1990, temos presenciado a emer- gência de uma geração, um grupo de intelectuais negros que não só tem contribuído para a reconfiguração do campo e da variação de temas de pesquisa quanto tem aliado de maneira criativa a atividade acadêmica e a prática política. $\mathrm{N}$ ão queremos dizer com isso que não houve importantes intelectuais negros no passado, a exemplo de M ilton Santos e Edson Carneiro, mas apenas sal ientar que esta é a primeira geração, no sentido da existência de um número mais expressivo de negros, que busca prosseguir e afirmar-se na vida acadêmica. A existência da Associação de Pesquisadores $N$ egros é um bom exemplo dessa mudança.

Londa Schienbinger (2001) demonstrou como a entrada das mulheres na atividade acadêmica não só alterou a agenda de pesquisa, como contribuiu para a ampliação dos temas e perspectivas adotadas. 0 mesmo poderíamos dizer acerca dos estudos sobre homossexual idade levados a cabo por pesquisadores homossexuais. N esse sentido, podemos constatar os diversos aspectos positivos derivados da entrada no campo de pesquisadores membros de grupos minoritários e integrantes do grupo pesquisado.

Entretanto, se esta reflexão positiva ocorre com relação à entrada de outros grupos, o mesmo não acontece no que diz respeito à inserção de alunos negros no campo de Estudos das $\mathrm{H}$ ierarquias $\mathrm{R}$ aciais no Brasil. N este campo, os pesquisadores negros não só historicamente estiveram à margem, como ainda, na maioria das vezes, são tratados com desconfiança, já que a proximidade com o tema e a perspectiva política presente nos estudos muitas vezes servem de argumento para desqualificar a produção de intelectuais negros, por estarem demasiadamente próximos do objeto e, portanto, supostamente não terem a necessária objetividade para analisar um fenômeno social do qual fazem parte.

Esse tipo de argumento é justamente o contrário do que nos sugere Patricia H ill C ollins (1990), quando destaca as questões relacionadas às implicações da posicionalidade na produção do conhecimento. Collins aponta a noção de stand point como um lugar privilegiado, um lugar historicamente construído e através do qual é possível observar/ compreender aspectosimportantes do grupo quando se é parte dele.

\section{Políticas descoloniais do conhecimento}

Esse tema tem sido discutido por vários autores e em diferentes perspectivas. As feministas negras norte-americanas e chicanas - pessoas de origem mexicana nascidas nos Estados U nidos - (M oraga e A nzaldúa, 1983), assim como alguns pensadores do Terceiro $\mathrm{M}$ undo, dentro e fora dos centros metropo- 
litanos (M ignolo, 2000), lembram constantemente que sempre falamos de uma local ização particular nas relações de poder. $\mathrm{N}$ inguém escapa às hierarquias de classe, raciais, sexuais e de gênero, linguísticas, geográficas e espirituais do sistema-mundo. A feminista norte-americana D onna $\mathrm{H}$ araway (2004) enfatiza que nossos conhecimentos sempre estão situados. As feministas negras têm denominado essa perspectiva da epistemologia de "ponto de vista afro-centrado" (C ollins, 1990). Entretanto, o filósofo da liberação latino-americano Enrique D ussel, desde os anos 1970, a define como "geopolítica do conhecimento" (D ussel, 1977). Seguindo o pensador afro-caribenho Frantz Fanon (2007) e a feminista chicana G loria A nzaldúa (1987), deveríamos falar também do "corpo-política do conhecimento".

Essa estratégia epistêmica tem sido crucial para os desenhos imperiais/globais ocidentais e para a hegemonia dos brancos crioulos nas A méricas. Por meio do encobrimento da localização particular do sujeito de enunciação, foi possível para a expansão e a dominação coloniais europeias/ euro-norte-americanas e para o poder das elites euro- latino-americanas construir uma hierarquia do conhecimento superior versus conhecimento inferior e, portanto, de seres superiores versus seres inferiores no mundo. Passamos de povos sem escrita no século XVI a povos sem história no século XV VIII, a povos sem civilização no século XIX, a povos sem desenvolvimento em meados do século $X X$ e, agora, a povos sem democracia no início do século XX I. Passamos dos direitos dos povos no século $X V I$ aos direitos dos homens no século XVIII e aos direitos humanos no final do século $X X$. Todos esses discursos fazem parte dos desenhos globais imperiais articulados à simultânea produção e reprodução da divisão internacional do trabalho entre centros e periferias que se superpõem de manei ra complexa entrelaçados às hierarquias etnorraciais globais entre europeus e não europeus, entre euro-brasileiros e o povo.

A produção do conhecimento nas universidades brasileiras, como em todas as universidades ocidentais, privilegia a epistemologia eurocêntrica da egopolítica do conhecimento. Essa epistemologia contribui para encobrir as hierarquias de poder raciais hegemônicas nos espaços universitários. A epistemologia branca da egopolítica do conhecimento, ao ser normalizada como a epistemologia do senso comum nos espaços universitários, está inscrita como neutra, universalista e objetiva. A perspectiva particular do homem branco se ergue como a norma universal de produção de conhecimentos, por meio da qual se medem e avaliam todas as outras formas de produzir conhecimentos. 0 homem branco pensa desde uma geopolítica e corpo-política do conhecimento particular, como homem, branco e privilegiado; porém, em nome de um suposto universalismo, encobre sua localização, recorrendo ao mito que Ihe permite pen- sar fora do corpo e fora do tempo e do espaço. Por isso mesmo, qualquer demanda de acadêmicos negros que reivindique sua própria geopolítica e corpo-política do conhecimento é imediatamente rechaçada pela grande maioria dos universitários brancos como uma perspectiva particular e parcial, quando não a denominam de essencialista.

Q uando aludimos à posicionalidade, não estamos nos referindo apenas a uma questão de valores sociais na produção do conhecimento, ao fato de que nossos conhecimentos são sempre parciais, perspectiva já bastante abordada dentro das $\mathrm{C}$ iências Sociais. 0 ponto central aqui é o lugar da enunciação, isto é, a localização étnica, sexual, racial, de classe e de gênero do sujeito que enuncia. $\mathrm{N}$ a filosofia e nas ciências ocidentais, o sujeito que fala está sempre encoberto; a localização do sujeito que enuncia está sempre desconectada da localização epistêmica. Por meio desta desconexão entre a localização do sujeito nas relações de poder e a localização epistêmica, a filosofia ocidental e suas ciências conseguiram produzir um mito universalista que encobre o lugar de quem fala e suas localizações epistêmicas nas estruturas de poder. Isto é 0 que 0 filósofo colombiano Santiago Castro-Gomez (2003) chamou de epistemologia do "ponto zero", que caracteriza as filosofias eurocêntricas. 0 "ponto zero" é o ponto de vista que esconde e encobre seu próprio ponto de vista particular, isto é, a construção de um ponto de vista que representa a si mesmo como não tendo nenhum ponto de vista e, portanto, almeja ser neutro e universal.

\section{Colonialidade do poder e a negação do racismo no espaço acadêmico}

Ainda que a maioria dos brasileiros reconheça que o Brasil é uma sociedade desigual racialmente, há controvérsias não somente acerca dos motivos ou da origem da desigualdade racial e da forma de combatê-la, mas ainda em relação à enorme dificuldade de identificar práticas racistas no cotidiano da sociedade brasileira. D esde as pesquisas desenvolvidas por Florestan Fernandes, temos conhecimento de que os brasileiros têm preconceito de ter preconceito. Essa característica do racismo à brasileira é corroborada por pesquisas mais recentes. Lilian Schwarcz, analisando os dados de uma pesquisa realizada pela U SP em 1988, demonstra que:

$97 \%$ dos entrevistados afirmaram não ter preconceito, $98 \%$ disseram conhecer, sim, pessoas e situações que revelam a existência de preconceito racial no país. Ao mesmo tempo, quando inquiridos sobre o grau de relação com aqueles que denominam racistas, os entre- 
vistadosindicaram com freqüência parentes próximos, namoradose amigosíntimos. A conclusão informal da pesquisa era, assim, que to do brasileiro parece se sentir como uma "ilha de democracia" cercado de racistas por todos os lados. (Schwarcz, 2001, 76)

Dados da pesquisa feita pelo Datafolha em 1995 reafirmam esta tendência ao revelar que "apesar de $89 \%$ dizerem haver preconceito de cor contra negros no país, só 10\% reconhecem ter preconceito" (SchwarCz, 2001, 77). Como parte da mesma moeda, ou como uma regra que se aplica a quem discrimina e a quem é discriminado, na pesquisa que realizamos sobre os negros de classe média, enfatizamos a dificuldade que os entrevistados tinham de mencionar que haviam sito vítimas de discriminação. M uitas vezes, eles recorriam à estratégia de mencionar um caso detal hado de discriminação ocorrido com terceiros, frequentemente, com parentes ou amigos muito próximos, o que demonstrava que o fato havia ocorrido com eles mesmos (Figueiredo, 2003)

Do mesmo modo, os brasileiros estão convencidos da existência do preconceito e da discriminação raciais, mas, na maioria das vezes, eles não acreditam que isto afete mais profundamente a vida daqueles que são discriminados, menos ainda que comprometa 0 desempenho escolar das crianças e jovem negros, as suas expectativas de vida e, efetivamente, as escol has profissionaise as chances de obter bons trabalhos. $\mathrm{N}$ ão só o Brasil é um país em que existe racismo sem que haja racistas, como o racismo é visto como algo abstrato. Q uase todos concordam com a existência das desigualdades raciais, mas é quase impossível constatar o racismo existente em nossa sociedade.

Para a grande maioria dos brasi leiros, a discriminação racial ainda é vista como sinônimo de interdição, impossibilidade de entrar em algum lugar. É claro que isso resulta da histórica comparação entre as relações raciais brasileiras e estadunidenses, em que os autores frequentemente destacavam a ausência de segregação racial oficial no Brasil em oposição aos Estados U nidos, além da suposta benevolência do colonizador português e da miscigenação como importantes fatores que contribuíram para tornar as relações raciais no Brasil mais amenas. 0 apartheid na África do Sul também era usado como um exemplo importante para se opor às práticas oficiais de segregação racial.

Essa mesma dificuldade ocorre com alguns acadêmicos e intelectuais brasileiros, que têm enorme dificuldade em reconhecer 0 racismo institucional existente no espaço universitário, como associado às práticas cotidianas que desqualificam ou desestimulam a trajetória de acadêmicos negros.

$\mathrm{Num}$ outro texto (Figueiredo e Grosfoguel, 2007), observamos que, consciente ou inconscientemente, raramente os autores negros estão nas bibliografias dos cursos ministrados nas universidades. C on- sequentemente, poucas vezes temos a oportunidade de conhecer a contribuição desses autores, refletindo, inclusive, não apenas sobre o conteúdo de seus trabalhos, mas sobre o contexto político-intelectual em que foram produzidos. Definimos essa prática como "política do esquecimento".

Durante a nossa formação, não temos tido a oportunidade de ler e conhecer a contribuição de intelectuais negros - talvez a exceção à regra seja Edson C arneiro. Essa ausência de referência contribui, sobremaneira, para a sensação de estarmos "fora do lugar", ou de sempre nos considerarmos pioneiros.

A lém disso, temos refletido pouco sobre a eficácia do discurso sobre a desigualdade de classe no Brasil e, consequentemente, sobre o preconceito e a discriminação de classe que perdura em nossas representações até hoje. D esde crianças, somos socializados para percebemos a desigualdade de classe - quando visitamos um bairro cujos habitantes são majoritariamente, quando não exclusivamente, brancos, denominamoso local de bairro de classe média, e não como bairro de brancos; o mesmo ocorre com as escolas, sempre referidas a partir da classe, e não da cor. Frequentemente, quando somos excluídos, tendemos a interpretar a exclusão a partir da classe, e não da cor. Essa dimensão das representações sobre a sociedade brasi leira dificulta não só a visibilidade de práticas racistas em nosso cotidiano quanto contribui para a rejeição a políticas públicas voltadas para segmentos específicos da população com base na cor/ raça.

Efetivamente, conhecemos muito pouco sobre 0 cotidiano dos alunos negros e de como se presentifica o racismo nas suas diferentes formas e manifestações (negação/rejeição/ estereótipos) dentro das universidades brasileiras. U $m$ dos poucos exemplos a que tivemosacesso éo de A ri Lima. Lima (2001) narra um fato ocorrido na U nB em 1998, em que foi reprovado em uma disciplina sem que houvesse uma chance sequer de diálogo entre ele e o professor que o desqual ificou, chamando-o de medíocre. A pós o resultado indicando sua reprovação, Lima apelou a três instâncias dentro da universidade, solicitando que o seu caso fosse revisto, sem que obtivesse êxito. $\mathrm{N}$ a quarta tentativa, felizmente, a nota atribuída foi revista, e A ri Lima foi aprovado na disciplina. Com relação ao período que marcou duramente a sua trajetória, ele afirma:

Acredito que se pode ver nesse 'drama social' forte indício de crime de racismo. Entretanto, como proválo? Q uais dados, palavras, ideias, representações, categorias podem sustentar esta suspeita? 0 que posso realmente falar sobre isso? Ao contrário, recebi fortes pressões para que eu me calasse, inclusive de professores do PPGAS. Confesso que nunca me senti tão bloqueado ou repercutindo o abandono histórico ao qual o segmento social a que pertenço foi relegado. (Lima, 2001, p. 311) 
É preciso produzir maior conhecimento sobre o dia a dia dos alunos negros nas universidades, já que a maioria das pesqui sas gira fundamental mente em torno de dados estatísticos, sinalizando para o maior ou o menor percentual de alunos negros em determinados cursos. Há também pouca ou quase nenhuma informação acerca da composição etnicorracial dos professores - a exceção é a pesquisa de C arvalho (2003), que, num instigante artigo, não só reafirma a sua posição favorável à política de reserva de vagas para negros e indígenas nas universidades quanto argumenta em prol da reserva de vagas na pós-graduação e nos concursos públicos para professores negros. De acordo com ele, menos de $1 \%$ do universo de professores das universidades públicas é formado por negros.

0 número total de docentes atual mente ativos nas 53 universidades federais é de aproximadamente 46.679 . A té onde sabemos, não deve passar de 2000 número de professores negros em todas essas universidades. (Carvalho, 2003, p. 329)

Vale a pena perguntar-se como foi possível um grau de exclusão racial tão escandaloso não tenha suscitado, até agora, praticamente nenhuma discussão ou mesmo incômodo por parte dos acadêmicos brancos brasileiros. (C arvalho, 2003, p. 329)

Embora haja controvérsia acerca das estatísticas apresentadas por $\mathrm{C}$ arval ho por parte de alguns intelectuais brancos e mestiços claros, muitos deles, inclusive, favoráveis à política de cotas - já que o consideram exagerado -, inclinamo-nos a considerar com seriedade esses dados, não só por nossa própria experiência quanto, e mais importante, pelo fato de não haver nenhuma pesquisa que conteste os números exibidos por ele.

A lém disso, Carval ho contesta o suposto discurso universal ista presente nos argumentos relativos aos preenchimentos de vagas por concursos públicos, quer sejam para professores ou para a pós-graduação.

O s concursos para docentes preenchidos quase que exclusivamente por candidatos brancos já não podem ser vistos apenas como resultado de decisões racionais, baseados em padrões inteiramente impessoais dos membros das bancas. 0 s concursos são na verdade o resultado de uma complexa equação que envolvem variáveis como: a política acadêmica (pressões internas e externas a favor de um determinado candidato); as redes de relações dentro da comunidade acadêmica (linhas de pesquisas, filiações teóricas, campos de atuação); além, é claro, do desempenho e da trajetória acadêmica (artigose livros publicados, experiência em pesquisa). (C arvalho, 2003, p. 310)

Essa prática de exclusão si stemática de professores negros não é recente. D ois exemplos são bem conhe- cidos do público brasileiro: Guerreiro R amos e Edson $\mathrm{C}$ arneiro, intelectuais negros ou morenos escuros, que em diferentes momentos foram impossibilitados de ingressar na extinta U niversidade do Brasil, atual U FR J. A lguns autores tentaram entender os motivos que levaram à marginalização de Guerreiro R amos no meio acadêmico. Oliveira (1995) alude ao fato de ele ter reagido aos cânones institucionais das $C$ iências Sociais brasileiras; Chor M aio (2004) destaca como motivo mais importante o fato de Guerreiro ter sido integralista - movimento político e ideológico de inspiração fascista ocorrido no B rasil na década de 1930, que buscava um Estado autoritário e nacionalista. $\mathrm{O}$ utros importantes personagens, a exemplo de $\mathrm{Hel}$ der C âmara e Alceu A moroso Lima, também foram envolvidos com o integralismo, entretanto, conseguiram desvincular seus nomes dessa experiência. $N$ esse sentido, portanto, o passado de extrema direita não é suficiente para explicar a marginal ização de G uerreiro $R$ amos. A lém do mais, Guerreiro tinha uma perspectiva segundo a qual a Sociologia era uma ciência engajada, ou uma Sociologia militante. Para Joel R ufino:

A explicação convencional é que houve nos últimos quarenta anos um forte deslocamento das relações de classe entre nós, e consequentemente, mudou a pauta da sociologia [... ] Há, contudo, uma explicação menos óbvia: os pensadores populistas jazem sob a montanha da modernização triunfante. (R ufino, 1995, p. 23)

A lgumas explicações sobre o esquecimento de Guerreiro $\mathrm{R}$ amos giram também em torno de sua personalidade. Todos que o conheceram concordam com o fato de Guerreiro ser extremamente polêmico, controverso e disposto a embates teóricos e políticos não muito frequentes na academia branca brasileira.

Ainda que tenham encontrado respostas plausíveis para a exclusão de Guerreiro, nenhum dos autores citados aludiu à questão de ele ser negro num contexto em que havia e, ainda há, poucos autores negros nas $\mathrm{C}$ iências Sociais. D esse modo, as referências ao fato de Guerrei ro ter sido preterido nas duas vezes que disputou uma vaga para professor universitário giram em torno do passado integralista, portanto, remetendo-se à afiliação política e não à sua condição racial. Guerreiro foi integralista num período em que ainda era muito jovem, mas essa marca, essa identificação com a extrema direita, perdurou durante toda a sua vida. A qui, seria interessante indagar sobre qual o significado de pertencer à esquerda naquele período, e qual o projeto apresentado pela esquerda à população negra. C omo explicar o fato de Guerreiro ter assumido a função de técnico em administração em 1943, no Departamento Administrativo do Serviço Público (D asp), quando deveria ser professor universitário?

R espaldando a crítica apresentada por C arvalho, gostaríamos de citar como exemplo o caso de uma uni- 
versidade federal em que os últimos três concursos no Departamento de A ntropologia foram preenchidos, exclusivamente, por pesquisadores brancos e estrangeiros. ${ }^{1}$ Frequentemente, 0 argumento utilizado para justificar essa tendênda gira em torno da ausência de candidatos negros ou do despreparo dos poucos candidatos negrosins critos quando comparados à incontestável competência/ genialidade dos candidatos brancos. Entretanto, ninguém ousa perguntar sobre o efeito perverso e desestimulante desses resultados para os poucos candidatos negros que ousam concorrer a um lugar de professor na referida universidade e tampouco buscam entender o porquê de as universidades federais constituírem um espaço majoritariamente branco, muitas vezes em cidades em que a maioria absoluta da população é negra. Parafraseando Schwarcz, acreditamos que essas universidades são "ilhas de brancos cercados de negros por todos os lados".

Como dissemos anteriormente, embora concordem que há poucos professores negros nas universidades públicas federais, muitos acreditam que os resultados dos concursos derivam apenas de avaliações objetivas (constituídas da avaliação do currículo, prova escrita, prova didática e entrevista), em que o mérito e não a pertença etnicorracial, as redes e as conexões acadêmicas e a trajetória importam.
Desse modo, percebemos que, mesmo quando encontramos exemplos de prática sistemática da exclusão de professoresnegros das universidades públicas brasileiras, há uma enorme dificuldade de entender tal atuação como reflexo, como prática resultante de uma cultura racista que é internal izada e reproduzida, mesmo quando se acredita imparcial. M as, afinal de contas, como comprovar a existência de discriminação racial diante de atitudes supostamente tão universalistas, em que se procura, pelo bem do conhecimento produzido na universidade, identificar apenas o meIhor candidato e, se coincidentemente, os negros não foram aprovados é porque efetivamente eles não são/ foram suficientemente bons para ocupar o cargo?

Q ueremos prevenir de antemão àqueles que podem, numa atitude simplista, tentar desqualificar 0 nosso argumento, intitulando- 0 de racismo às avessas, ou de racismo contra branco, de que não é fácil chegar a esta conclusão. A té porque, como parte do universo acadêmico, também aprendemos a adotar um discurso universalista e meritocrático, assim como também tivemos uma formação voltada para entender o racismo e a discriminação racial e de gênero que ocorrem fora do espaço universitário - afinal de contas, "racistas são sempre os outros".

1 Dois concursos foram realizados para a disciplina de Antropologia na própria universidade e o último concurso, em 2006, sob a responsabilidade do Departamento de Antropologia, foi para o preenchimento de vagas para uma nova universidade federal.

\section{Referências}

AN ZALDÚA, Gloria. B ordelands/ L a Fronteira: the new mestiza. San Francisco: Aunte Lute, 1987.

CAR VA LHO, José Jorge. As ações afirmativas como resposta ao racismo acadêmico e seu impacto nas $C$ iências Sociais brasileiras. Teoria e pesquisa, n. 42/43, p. 303-340, 2003.

; SEGATO, R ita. U ma proposta de cotas para estudantes negros na U niversidade de Brasília. Série A ntropologia, n³14. Brasília: U nB, 2002.

CASTRO-GOMEZ, Santiago. La hybris del punto cero: ciencia, raza e ilustración en la N ueva Granada (17501816). Bogotá: Pontifica U niversidade Javeriana, 2003.

COLLINS, Patricia Hill. Black feminism thought: knowledge, consciousness and the politics of empowerment. N ew York: R outledge. 1990.

CÔR R EA, M ariza. 0 mistério dos orixás e das bonecas. In: Ed. UFM G, 2003.

DU SSEL, Enrique. Filosofía de la liberación. M éxico: Edicol, 1977.

FAN ON, Frantz. Pele negra, máscara branca. Salvador: Ed.U FBA, 2007.

FIGU EIR EDO, Ângela. A dasse média negra nâo vai ao pa- raíso: perfil, trajetória e identidade entre os empresários negros. R io de Janeiro, 2003. Tese (D outorado em Sociologia) - Iuperj.

; GR O SFO GU EL, R amón. Por que não Guerreiro $\mathrm{R}$ amos? N ovos desafios a serem enfrentados pelas universidades públicas brasileiras. C iência e C ultura, ano 59, n. 2, p. 36-41, 2007.

GR O SFO GU EL, R amón. C olonial subjects: puerto ricans in a global perspective. Berkeley: U niversity of $\mathrm{C}$ alifornia Press, 2003.

- Subaltern epistemologies, decolonial imaginaries and the redefinition of global capitalism. R eview: a journal of the Fernand Braudel Center, v. 28, 2005.

H AR AWAY, Donna. "Gênero" para um dicionário marxista: a política sexual de uma palavra. C adernos Pagu, $\mathrm{n}$. 22, p. 201-246, 2004.

H ASEN BALG, Carlos. D iscriminação e desigualdades raciais no $B$ rasil. $R$ io de Janeiro: G raal, 1979.

LIMA, A ri. A legitimação do intelectual negro no meio acadêmico brasileiro: negação de inferioridade, confronto ou assimilação intelectual. A fro- Á sia, n. 25/26, p. 281-312, 2001.

M ALDONADO, N elson. Pensamento crítico desde a su- 
balteridade: os Estudos Étnicos como ciências descoloniais ou para a transformação das humanidades e das ciências sociais no século X X I. A fro-Á sia, n. 34, p. 105-129, 2006. M AGGIE, Y vonne; FR Y, Peter. 0 debate que não houve: a reserva de vagas para negros nas universidades brasilei ras. E nfoques: R evista eletrônica dos alunos do IFC S/U FR J, v. 1, n. 1, p. 93-108, 2002. Disponível em: <http:// ww w.enfoques.ifcs.ufrj.br/pdfs/dezembro2002.pdf>. Acesso em: 24 mar. 2009.

M AIO, M arco Chor. A história do Projeto U nesco: estudos raciais e ciências sociais no Brasil. R io de Janeiro, 1997. Tese (D outorado em Ciência Política) - I uperj.

. 0 'Projeto U nesco de relações raciais' e as trocas intelectuais e políticas Brasil-EU A . Interseç̃es, v. 6, n. 1, p. 123-142, 2004.

; SANTOS, R icardo Ventura. Políticas de cotas raciais, 'os ol hos da sociedade' e 0 uso da antropologia: 0 caso do vestibular da U niversidade de Braślia (U nB). H oriz ontes A ntropológicos, v. 11, n. 23, p. 181-214, 2005.

M IG N O LO, W alter. L ocal histories/global designs: essays on the coloniality of power, subaltern knowledges and border thinking. Princeton: Princeton U niversity Press, 2000.

MOR AGA, Cherríe; ANZALDÚA, Gloria (O rg.). This bridge called my back: writings by radical women of color. N ew York: K itchen Table, 1983.

N O GU EIR A, O racy. Preconceito de marca: as relações raciais em Itapetinga. São Paulo: Edusp, 1998.

O LIVEIR A, Lucia Lippi. A sociologia do G uerreiro.R io de Janeiro: Ed. U FR J, 1995.

PEN A, Sérgio D. J.; BORTO LIN I, M aria Cátira. Pode a genética definir quem deve se beneficiar das cotas universitárias e demais ações afi rmativas? E studos A vançados, v. 18, n. 50, p. 31-50, 2004.

QU IJAN O, A níbal. 'R aza', 'etnia' y 'nación' en M ariátegui: cuestiones abiertas. In: FOR GUES, R oland (Ed.). José $C$ arlos $M$ ariátegui y $E$ uropa: el otro aspecto del descubrimiento. Lima: A mauta, 1993. . La colonialidad del poder y la experiencia cultural latinoamericana. In: BR ICEÑ O - LEÓ N , R oberto; SO N N TAG , H einz R . (Eds.). Pueblo, época y desarrollo: la Sociología de A mérica Latina. C aracas: N ueva Sociedad, 1998. . Coloniality of power, ethnocentrism, and Latin A merica. N epantla, v. 1, n. 3, p. 533-580, 2000.

R AM OS, A lberto Guerreiro. Introdução crítica à sociologia brasileira. R io de Janeiro: Ed. U ER J, 1995. . A redução sociológica. R io de Janeiro: Ed. U FR J, 1996.

R U FIN O, Joel. Introdução. In: R A M OS, A lberto Guerreiro. Introdução crítica à sociologia brasileira. $R$ io de Janeiro: Ed. U ER J, 1995.

SCHIEN BINGER, Londa. 0 feminismo mudou a dência? Bauru, SP: Edusc, 2001.

SCH WAR CZ, Lilia M oritz. R acismo no Brasil. São Paulo: Publifolha, 2001.

SK ID M OR E, Thomas E. B lack into white: race and nationality in Brazilian though. $\mathrm{N}$ ew York: $\mathrm{O}$ xford U niversity Press, 1974.

. $R$ ace and class in Brazil: historic perspectives. In: FON TAIN E, Pierre-M ichel (Ed.). R ace, dass and power in B razil. Los A ngeles: U niversity of C alifornia Press, 1980. 


\title{
Racism in the brazilian way or racism without racists: coloniality of power and denial of racism in the university environment
}

\begin{abstract}
The adoption of a quota system by the Brazilian Public U niversities has aroused an intensive and heated debate among several antiracist Brazilian intellectuals who aim to build a fairer society, but who also place themselves in opposite positions when the theme is the implementation of quotas. The negative reaction of white as well as mixed-race scholars, from both the left and the right wings, against this quota system is due to their concern about the possibility that B razil might become a racist country thus rejecting the positive connotation traditionally attached to our racial mixture. In this article we use A níbal Q uijano's concept of colonialility of power. Accordingly, the article discusses the importance of the geopolitics of knowledge since it is crucial that we understand the epistemic location and the positions taken by different social actors.
\end{abstract}

Key words: racial inequalities; racial hierarchies; coloniality of power; geopolitics of knowledge; modernity.

\section{El racismo en Brasil o el racismo sin racistas: la colonialidad del poder y la negación del racismo en el espacio universitario}

\begin{abstract}
Resumen
La adopción del sistema de cuotas en las U niversidades Públicas Brasileñas ha suscitado intenso y caluroso debate entre los intelectuales brasileños antirracistas, que anhelan la construcción de una sociedad más justa, pero están en contra al tema de la implementación de las cuotas. La reacción negativa de esos interlocutores blancos y mestizos claros, de izquierda y de derecha, con relación a las políticas de cuotas, deriva de la preocupación con la posibilidad de crearse un Brasil de razas, destruyendo, así, nuestro tan caro discurso de mestizaje. A bordamos, en este texto, el tema de la perspectiva de la colonialidad del poder articulada por A níbal Q uijano. D esde esa perspectiva, nos parece importante entender la importancia de la geopolítica del conocimiento, ya que es determinante que comprendamos la localización epistémica y las posiciones tomadas por los diferentes actores sociales.
\end{abstract}

Palabras clave: desigualdades raciales; jerarquías raciales; colonialidad del poder; geopolítica del conocimiento; modernidad. 
